\title{
Dimethyl Fumarate in the Treatment of Relapsing-Remitting Multiple Sclerosis: Patient Reported Outcomes and Perspectives
}

This article was published in the following Dove Press journal: Patient Related Outcome Measures

\author{
Osman Ozel $\mathbb{D}^{\prime}$ \\ Caila B Vaughn (D) \\ Svetlana P Eckert $\mathbb{D D}^{\prime}$ \\ Dejan Jakimovski (iD) ${ }^{2}$ \\ Alexis A Lizarraga $\mathbb{( D}^{\prime}$ \\ Bianca Weinstock- \\ Guttman (D)' \\ 'Jacobs MS Center for Treatment and \\ Research, Department of Neurology, \\ Jacobs School of Medicine and Biomedical \\ Sciences, State University of New York at \\ Buffalo, Buffalo, NY, USA; ' ${ }^{2}$ Buffalo \\ Neuroimaging Analysis Center, \\ Department of Neurology, Jacobs School \\ of Medicine and Biomedical Sciences, \\ University at Buffalo, State University of \\ New York, Buffalo, NY, USA
}

Correspondence: Bianca WeinstockGuttman

Jacobs MS Center for Treatment and Research, Department of Neurology, Jacobs School of Medicine and Biomedical Sciences, State University of New York at Buffalo, 1010 Main Street, $2^{\text {nd }}$ Floor

Buffalo, NY 14202, USA

Tel +l 7168295063

Fax + I 7168294001

Email bw8@buffalo.edu

\begin{abstract}
Dimethyl fumarate (DMF) is a commonly prescribed oral medication for the treatment of relapsing forms of multiple sclerosis (MS) with a wide range of hypothesized downstream mechanisms of action. Randomized clinical trials have established its clinical efficacy by using standard objective clinical measures. However, MS is a chronic disease that, apart from physical ailments, can affect an individual's mood, psychosocial status, and quality of life which cannot be captured by using only objective assessment tools. Given the challenge of determining the efficacy of the treatment in a real-world clinical setting, the use of patient-reported outcomes (PROs) may help us to better address these aspects of patient care and establish a more patient-centered approach to MS care. To date, a review of PubMed identified six studies which reported on PROs in patients who are taking DMF. In total, twelve different kinds of PRO measures were utilized and 6359 patients provided at least one form of PRO in these studies. Upon review of these studies, we were able to conclude that people with MS had decreased quality of life compared to the healthy population in the US. MS patients on DMF, however, had better health-related quality of life assessment scores compared to those using a placebo. Previous studies also suggested that DMF decreased work productivity impairment scores after one year of use compared to baseline. DMF was associated with less impairment in fatigue and depression scales along with improved treatment quality assessment and adherence scores. This review will present a brief synopsis of the published literature and will provide indications for future directions with respect to PROs and DMF in people with MS.
\end{abstract}

Keywords: multiple sclerosis, patient-reported outcomes, outcome measures, quality of life, dimethyl fumarate

\section{Introduction}

Multiple sclerosis (MS) is a chronic, demyelinating and neurodegenerative disease that affects the central nervous system (CNS). It often presents in early adulthood with a lifelong impact. Approximately $80 \%$ of patients with MS present with an initial relapsing-remitting disease course (RRMS), characterized by periods of acute episodes of focal neurological deficits followed by recovery, which is amenable to treatment with disease-modifying therapies (DMTs). Eventually, a significant number of these individuals will progress to secondary progressive MS (SPMS) where neurological disability accumulates. A smaller proportion of individuals present with primary progressive MS (PPMS) characterized by progressive accumulation of neurological disability from the onset of the disease without superimposed acute events. 
There are currently over a dozen DMTs that have been approved by the United States Food and Drug Administration (FDA) for the treatment of relapsing forms of MS. This review will focus on patient reported outcomes while on dimethyl fumarate (DMF) therapy, one of the most frequently used firstline therapies worldwide. DMF is an easy-to-use, effective, and generally well-tolerated oral medication that is FDAapproved for relapsing MS (relapsing remitting [RRMS] and active secondary progressive [SPMS]). DMF has demonstrated clinical efficacy in two randomized, double-blind, placebo-controlled clinical trials - DEFINE $^{1}$ and CONFIRM. ${ }^{2}$ These trials established that DMF was superior to placebo in reducing annualized relapse rate (ARR), ${ }^{1,2}$ disability progression, ${ }^{1}$ occurrence of gadolinium-enhancing lesions, ${ }^{1}$ and occurrence of new or enlarging T2-weighted hyperintense lesions $^{1,2}$ on MRI. As of January 31, 2019, more than 385,000 patients have been treated with DMF, which represents over 710,000 years of patient exposure (unpublished data: Tecfidera Patient Exposure; Biogen Medical Information; 2019). DMF is taken twice daily and has afavorable safety profile compared to other available oral therapies for the treatment of MS. ${ }^{3}$ Given its wide utilization, it is important to examine realworld patient-reported indicators of efficacy and satisfaction with this therapy. In the DMT era for MS, there has been an increasing emphasis on apatient-centered approach to clinical management. ${ }^{4}$ It has become more apparent that there is some discrepancy between patients and physicians with respect to the perception of disease impact and quality of life (QoL), both among persons with MS (PwMS) and among other disease states. ${ }^{5,6}$ Therefore, for best medical management, it is critical to understand patients' perceptions regarding disease symptomology and treatment efficacy, as well as the limitations they are experiencing. Though still underutilized, researchers and clinicians have begun to recognize the value of patientreported outcomes (PROs) and have begun to incorporate them into research studies and clinical practice with an increasing number of different PROs. However, it is challenging to establish valid PRO measures which can be easily utilized longitudinally in routine clinical practice as well as in research studies. Despite efforts to do so, there is still alack of gold standard PRO measures in general, and specifically in the MS field.

Given the wide-utilization of DMF and the increasing importance of PROs in assessing treatment efficacy in MS, the objective of this review is to examine studies which have assessed the effect of DMF as a treatment for MS on PRO measures. We will present some of the more commonly used PROs in MS and will summarize the results
Table I Literature Search Criteria

\begin{tabular}{|l|l|}
\hline Database & PubMed, Google Scholar \\
\hline Date & 1985 - July 2019 \\
\hline Eligibility criteria & Studies conducted on humans; Published in English \\
\hline MeSH Keywords/ & $\begin{array}{l}\text { "multiple sclerosis" AND "patient-reported } \\
\text { outcome", "multiple sclerosis" AND "quality of } \\
\text { life", "dimethyl fumarate" AND "patient- } \\
\text { reported outcomes", "dimethyl fumarate" AND } \\
\text { "quality of life" }\end{array}$ \\
\hline
\end{tabular}

Abbreviation: MeSH, Medical Subject Headings.

from published studies specific to the use of DMF. The literature search strategy is described in Table 1.

\section{Significance and Utility of Patient-Reported Outcomes in Multiple Sclerosis}

Patient-reported outcomes have been defined as outcomes obtained "directly from the patient, without interpretation of the patient's response by a clinician or anyone else,", and are typically obtained through self-administered questionnaires. PROs can comprise a variety of topics and many of the most commonly used PROs assess domains such as QoL, physical functioning and disease symptoms. PROs are particularly valuable in MS in part because the disease presentation is so variable. PwMS can present with a wide range of symptoms, from fatigue and depression to vision problems, to sensory symptoms and pain, to bowel and bladder difficulties and more. Additionally, PwMS often have a different perception of their disease than clinicians and PROs represent a means of capturing the overall patient experience that well-complements what is observed during the neurological exam. ${ }^{5,8}$ It has also been documented that PwMS and their treating physicians have reported differences in the importance of various QoL indicators further indicating that concerns for patients are often different than concerns for physicians. ${ }^{9}$ Furthermore, a previous study has indicated that PROs were able to predict disability worsening among PwMS better when added to the objective clinical assessment. ${ }^{10}$

PROs are important for patients in a real-world setting, but also more recently the FDA has recommended inclusion of PROs as secondary and/or tertiary outcome measures in clinical trials. ${ }^{11}$ As the recognition of the value of PROs has increased, so has the number of existing PRO measures. Previous studies have estimated that there are 
over 400 published PROs overall and nearly 100 that are specific to MS. ${ }^{12}$ The most commonly utilized PROs for clinical trials were classified into the following domains: symptoms, function, QoL, caregiver burden and other (including self-efficacy and treatment satisfaction); ${ }^{12}$ see Table 2 for commonly used PROs in MS.

Though many of these PRO measures have been privately created and validated, other large organizations have developed PRO measures as well. For example, the US National Institutes of Health (NIH) funded an initiative to develop PRO measures - the Patient-Reported Outcomes Measurement Information System (PROMIS). ${ }^{13,14}$ The goal of this initiative was to create a publicly available PRO measure for several domains (health, physical function, fatigue, pain, sleep, emotional, and social health) that could be standardized across studies. Though not mandatory, the inclusion of these PROs in US federally funded studies is encouraged for standardization and comparison.

Finally, as part of the transition to the Merit-based Incentive Payment System under the Affordable Care Act for provider payments will be based on "quality of care" for Medicare reimbursement. The evaluation will include PROs as incentive-based performance systems and ultimately will serve to reward providers whose patients report improvement in patient-specific domains. ${ }^{15}$ Furthermore, utilizing PROs developed for the evaluation of health care in the incentivized systems will help to preserve a patientcentered approach in clinical care.

It is important to emphasize that the rapid development and use of PROs has not always been followed by rigorous validation and the determination of clinically meaningful change within individual measures. For many PROs not

Table 2 Patient-Reported Outcome Measures Frequently Used in Multiple Sclerosis

\begin{tabular}{|c|c|c|}
\hline Domain & Category & Name \\
\hline Health-related Quality of Life & MS-Specific & Functional Assessment of Multiple Sclerosis ${ }^{52}$ \\
\hline Health-related Quality of Life & MS-Specific & MSQoL ${ }^{53}$ \\
\hline Health-related Quality of Life & MS-Specific & MSQLI $^{51}$ \\
\hline Health-related Quality of Life & MS-Specific & HAQUAMS ${ }^{43}$ \\
\hline Health-related Quality of Life & Generic & SF- $36^{32}$ \\
\hline Health-related Quality of Life & Generic & $E Q-5 D^{33}$ \\
\hline Symptoms & Fatigue & Fatigue Severity Scale ${ }^{54}$ \\
\hline Symptoms & Fatigue & Modified Fatigue Impact Scale ${ }^{36}$ \\
\hline Symptoms & Fatigue & Unidimensional-Fatigue Impact Scale ${ }^{55}$ \\
\hline Symptoms & Fatigue & The Fatigue Scale for Motor and Cognitive Function ${ }^{56}$ \\
\hline Symptoms & Fatigue & The Neurological Fatigue Index-MS ${ }^{57}$ \\
\hline Symptoms & Total & Symptom Inventory ${ }^{58}$ \\
\hline Symptoms & Total & MS-Related Symptoms Checklist ${ }^{59}$ \\
\hline Symptoms & Other & MS Intimacy and Sexuality Questionnaire ${ }^{60}$ \\
\hline Symptoms & Other & Actionable Bladder Symptom Screening Tool ${ }^{61}$ \\
\hline Functioning & Functioning & Patient-Determined Disease Steps ${ }^{62}$ \\
\hline Functioning & Functioning & MS Rating Scale ${ }^{63}$ \\
\hline Functioning & Functioning & Multiple Sclerosis Impact Scale (MSIS-29) ${ }^{64}$ \\
\hline Functioning & Functioning & MS Walking Scale $-12^{65}$ \\
\hline Functioning & Functioning & LIFEware PRO ${ }^{66}$ \\
\hline Functioning & Functioning & Falls Prevention Strategies Survey ${ }^{67}$ \\
\hline Other & Employment & Work Productivity \& Activity Impairment: $\mathrm{MS}^{41}$ \\
\hline Other & Self-efficacy & MS Self-efficacy Scale (Rigby) ${ }^{68}$ \\
\hline Other & Self-efficacy & MS Self-efficacy Scale (Schwartz) ${ }^{69}$ \\
\hline Other & Self-efficacy & Liverpool MS Self-efficacy Scale ${ }^{70}$ \\
\hline Other & Self-efficacy & The Unidimensional Self-efficacy Scale for $\mathrm{MS}^{71}$ \\
\hline Other & Knowledge \& Acceptance & The Multiple Sclerosis Knowledge Questionnaire ${ }^{72}$ \\
\hline Other & Cognition & Multiple Sclerosis Neuropsychological Screening Questionnaire (MSNQ) ${ }^{73}$ \\
\hline Other & Cognition & Perceived Deficits Questionnaire ${ }^{74}$ \\
\hline Caregiver & Caregiver & Caregiving Tasks in $\mathrm{MS}^{75}$ \\
\hline Caregiver & Caregiver & Carer Sense Making Scale (CSMS) ${ }^{76}$ \\
\hline Caregiver & Caregiver & Benefit Finding in MS Scale ${ }^{77}$ \\
\hline
\end{tabular}


specific to MS, there is little explanation when choosing a PRO for use in PwMS, ${ }^{16}$ and often a measure may be chosen because of a lack of PROs validated in the MS population.

\section{Disease Modifying Therapies for Multiple Sclerosis}

Multiple sclerosis as a specific disease did not become recognized by the medical community until the 1870 s. Since that time, scientific discovery has provided us with invaluable insight into the MS disease pathogenesis and has led to the development of 19 different DMTs. It was not until 1993 that the first DMT shown to affect MS disease activity, interferon (IFN) beta $1 \mathrm{~b}$, was approved. Subsequently, several more injectable medications were developed, including intramuscular and subcutaneous IFN beta 1a, subcutaneous IFN beta $1 \mathrm{~b}$, and subcutaneous glatiramer acetate. Due to their excellent long-term safety, these medications are still frequently preferred by patients and clinicians, with their use limited primarily by tolerance issues related to injection site reactions, flu-like symptoms, and rarely depression.

A new era in MS treatment began in 2010, with the advent of oral medications. These include fingolimod, DMF, teriflunomide and, more recently, siponimod, cladribine and diroximel fumarate. Four other DMTs with intravenous route of administration including natalizumab, rituximab (use of which in MS is off-label), alemtuzumab and ocrelizumab also became available. Although intravenously-administered DMTs provide higher efficacy, better compliance and convenience (eg once a year dosing for alemtuzumab and twice a year dosing with ocrelizumab), they are also associated with a higher risk for side effects including opportunistic infections and possible cancer. Identification of the most appropriate therapeutic intervention for an individual patient is a challenge and is the subject of several large ongoing clinical trials.

The focus of this review is DMF, a twice-daily medication which has been widely used in the MS population, with a unique but not yet fully understood mechanism of action which may involve multiple downstream pathways.

\section{Dimethyl Fumarate}

DMF is a fumaric acid ester (FAE) and its mechanism of action is thought to be primarily mediated by its main metabolite, monomethyl fumarate (MMF), which is mostly produced via hydrolysis in the small intestine. Prior to
DMF's approval by the FDA for the treatment of RRMS in the United States in March 2013, other fumarate products were approved primarily for the treatment of psoriasis in Europe. DMF approval in the US was based primarily on two successful clinical trials: DEFINE (Determination of the Efficacy and Safety of Oral Fumarate in RelapsingRemitting MS) ${ }^{1}$ and CONFIRM (Comparator and an Oral Fumarate in Relapsing-Remitting Multiple Sclerosis). ${ }^{2}$ FDA approval was granted based on demonstrated efficacy in several clinical outcomes measures for MS: proportion of patients who had a relapse by 2 years (primary endpoint DEFINE) ${ }^{1}$ annualized relapse rate (ARR, primary endpoint CONFIRM) ${ }^{2}$ and various secondary efficacy endpoints (number of new or enlarging gadolinium-enhancing or hyperintense lesions on T2-weighted images, the number of new hypointense lesions on T1-weighted images, proportions of patients with a relapse and time to disability progression). ${ }^{1,2}$ Despite its approval and wide use, the exact mechanism of action of dimethyl fumarate is not fully elucidated ${ }^{17}$ and its effects on the immune system appear to be multifactorial.

There are several mechanisms by which DMF is considered to be effective in MS. The first identified beneficial mechanism of action for DMF in MS was primarily related to its anti-oxidant effects acting via nuclear factor erythroid-derived 2-related factor (Nrf-2) dependent and independent anti-oxidant pathways. ${ }^{18-21}$ $\mathrm{Nrf2}$ is a transcription factor important for maintaining cellular redox homeostasis. DMF activates Nrf2, allowing it to migrate to the nucleus and induce expression of genes for anti-oxidants and detoxifying enzymes, including hemoxygenase-1 (HO-1), NADPH quinone dehydrogenase (NQO-1), and glutathione S-transferase (GST-1). The downstream effects of these molecules have been shown to possess anti-inflammatory and antiproliferative activity. $^{18-21}$

DMF has also been shown to affect the proportions and phenotype of inflammatory immune cells toward favoring an anti-inflammatory state. With the administration of DMF, the number of proinflammatory $\mathrm{T}$ cells including CD8 $+\mathrm{T}$ cells, CD4+ T cells, CD19+ B cells, CD56 ${ }^{\text {dim }}$ NK cells, plasmacytoid DCs, and eosinophils are decreased. ${ }^{22,23}$ DMF can also reduce in vitro binding of T-cells to adhesion molecules (ie Intercellular adhesion Molecule 1 [ICAM-1]) and therefore prevent immune cell migration. ${ }^{24}$ In mouse models, DMF decreased the expression of integrin $\alpha 4$, on $\mathrm{CD} 3+\mathrm{T}$ and B220+ B cells and was shown to decrease the severity and incidence of the clinical scores, as well as delay the onset of 
experimental autoimmune encephalomyelitis (EAE). ${ }^{25}$ These effects are likely contributing to the reduction of overall CNS inflammation in MS patients treated with DMF. On the other hand, it has been suggested that DMF may confer neuronal protection against proinflammatory toxic microenvironments by altering microglia phenotype. ${ }^{26}$

DMF has been a widely-used MS medication since its initial FDA approval in 2013 which provided us with an extensive database on prior and ongoing assessment of medication-related efficacy and tolerability as well as side effects and adverse reactions. In the phase 3 studies of DMF, both DEFINE and CONFIRM, the adverse events which occurred at a higher incidence with active treatment than placebo included flushing and gastrointestinal events including diarrhea, nausea, and/or upper abdominal pain at a rate of $36 \%$ with twice-daily DMF in the CONFIRM trial. ${ }^{1,2}$ These adverse events were reported to subside after the first month of use. Allergic reactions as well as elevations in liver enzyme and bilirubin levels have also been reported, though in some cases transaminitis may be transient. ${ }^{27}$ In clinical practice, flushing and gastrointestinal adverse effects are the most common reasons people are unable to tolerate therapy with DMF. These effects can be mitigated by the administration of low dose aspirin prior to the DMF dose, and/or dose administration with food.

Lymphopenia is also a fairly common and potentially dangerous side effect of DMF seen in approximately $16.5 \%$ of patients ${ }^{28}$ contributing to the development of infections such as upper respiratory infections. More serious opportunistic infections, such as progressive multifocal leukoencephalopathy (PML) may also occur in patients on DMF. To date, seven PML cases have been reported in PwMS on DMF; six of those were associated with moderate to severe, prolonged lymphopenia (unpublished data; Tecfidera: PML Case Reports; Biogen Medical Information; 2019). Thus, current guidelines recommend lymphocyte count monitoring at baseline and at least every six months thereafter.

When considering initiation of DMF, all of the above potential side effects need to be considered with risks and benefits carefully weighed during a shared decision making with patient and family. What may add much more to the consideration of DMF as a therapy for a specific patient, are reports on PROs, which may assist in providing a more thorough assessment of the patient's day-to-day response and tolerability of the medication.

\section{Existing Literature on Dimethyl Fumarate and PROs PROs Assessed in Studies on DMF and MS}

To date, a review of Pubmed identified six published studies that have included the use of DMF as one of the treatment arms and have reported on PROs as secondary or tertiary end-points; these studies are presented in Table 3. Twelve distinct PRO measures have been reported in these studies. There are no studies on DMF which have reported on PROs as primary end-points.

\section{DEFINE, CONFIRM and an Integrated Analysis}

As previously described, DEFINE $^{1}$ and CONFIRM ${ }^{2}$ were two phase 3, placebo-controlled randomized clinical trials to assess the efficacy of DMF (240 mg), with twice-daily (BID) and thrice-daily (TID) arms. The CONFIRM study utilized a glatiramer acetate (GA) comparator arm as well. In both of these clinical trials PROs were reported as a tertiary outcome result. ${ }^{29-31}$ With respect to PROs, the Short Form-36 (SF-36) ${ }^{32}$ and the European Quality of Life-5D (EQ-5D), ${ }^{33}$ two wellknown health-related quality of life (HRQoL) questionnaires were assessed at baseline and six, twelve and twenty-four months. The SF-36 is a questionnaire with two separate components: a Physical Component Scale (PCS), measuring physical functioning, physical role, bodily pain, and general health, and a Mental Component Scale (MSC), comprised of assessments for vitality, social functioning, and emotional and mental health. ${ }^{32}$ The EQ-5D also includes two components: the EQ-5D and the EQ-VAS. The EQ-5D describes the patients' health status in five categories: mobility, self-care, usual activities, pain/discomfort, and anxiety/depression. The EQ-VAS is an integrated visual analog scale from 0 (the worst possible health status) to 100 (the best possible health status) wherein the patient is instructed to indicate his or her general health status by drawing a line on the scale at the time of the visit. ${ }^{33}$

Additionally, the Global Impression of Well-being Visual Analog Scale (GI-VAS) ${ }^{29}$ was assessed at baseline and every three months after. Scoring for the GI-VAS is similar to that for the EQ-VAS and results were given as the comparison of scores at two years to the baseline scores. Due to the similarity of the trials, an integrated analysis of both studies was published and will be referenced here. ${ }^{31}$

In the SF-36 analysis, PCS and MCS scores were below average for all arms at baseline, which indicated impairment of the HRQoL in PwMS. At the two-year follow-up, both DMF treatment arms showed a highly 
Table 3 Existing PRO Studies and Dimethyl Fumarate

\begin{tabular}{|c|c|c|c|c|c|c|}
\hline Study & N Patients & $\begin{array}{l}\text { Disease } \\
\text { Type }\end{array}$ & $\begin{array}{l}\text { Study } \\
\text { Design }\end{array}$ & $\begin{array}{l}\text { Time } \\
\text { Frame }\end{array}$ & $\begin{array}{l}\text { PROs } \\
\text { Used }\end{array}$ & Outcome \\
\hline DEFINE' & $\begin{array}{l}1234 \\
\text { DMF BID } \\
(n=4 \mid 0) \\
\text { DMF TID } \\
(n=4 \mid 6) \\
\text { Placebo } \\
(n=408)\end{array}$ & RRMS & $\begin{array}{l}\text { Double Blind, } \\
\text { Placebo } \\
\text { controlled }\end{array}$ & 24 months & $\begin{array}{l}\text { SF-36 } \\
\text { EQ-5D } \\
\text { Global } \\
\text { well-being- } \\
\text { VAS }\end{array}$ & $\begin{array}{l}\text { The scores from all measures } \\
\text { showed significant improvement } \\
\text { in the treatment group } \\
\text { compared to the placebo }\end{array}$ \\
\hline CONFIRM $^{2}$ & $\begin{array}{l}14 \mid 7 \\
\text { DMF BID } \\
(n=359) \\
\text { DMF TID } \\
(n=345) \\
\text { Placebo } \\
(n=363) \\
\text { GA }(n=350)\end{array}$ & RRMS & $\begin{array}{l}\text { Double Blind, } \\
\text { Placebo } \\
\text { controlled and } \\
\text { active } \\
\text { comparator }\end{array}$ & 24 months & $\begin{array}{l}\text { SF-36 } \\
\text { EQ-5D } \\
\text { Global } \\
\text { well-being- } \\
\text { VAS }\end{array}$ & $\begin{array}{l}\text { The scores from all measures } \\
\text { showed significant improvement } \\
\text { in the treatment group } \\
\text { compared to the placebo } \\
\text { There was no significant difference between DMF and } \\
\text { GA group }\end{array}$ \\
\hline $\begin{array}{l}\text { DEFINE/ } \\
\text { CONFIRM } \\
\text { Integrated } \\
\text { Analysis }^{31}\end{array}$ & $\begin{array}{l}2301 \\
\text { DMF BID } \\
(n=769) \\
\text { DMF TID } \\
(n=76 I) \\
\text { Placebo } \\
(n=771)\end{array}$ & RRMS & $\begin{array}{l}\text { Double Blind, } \\
\text { Placebo } \\
\text { controlled }\end{array}$ & 24 months & $\begin{array}{l}\text { SF-36 } \\
\text { EQ-5D } \\
\text { Global well- } \\
\text { being-VAS }\end{array}$ & $\begin{array}{l}\text { The scores from all measures } \\
\text { showed significant improvement } \\
\text { in the treatment group } \\
\text { compared to the placebo }\end{array}$ \\
\hline $\begin{array}{l}\text { Work } \\
\text { Productivity } \\
\text { Outcomes }\end{array}$ & $\begin{array}{l}31 \text { (DMF) } \\
229(\text { Beta-INFs } \\
\text { and GA) }\end{array}$ & RRMS & $\begin{array}{l}\text { Cross- } \\
\text { Sectional } \\
\text { Study }\end{array}$ & $\begin{array}{l}\text { Cross } \\
\text { Sectional }\end{array}$ & $\begin{array}{l}\text { HAQUAMS } \\
\text { EQ-5D } \\
\text { WPAI-MS }\end{array}$ & $\begin{array}{l}\text { The scores from all measures } \\
\text { was significantly better in the DMF group } \\
\text { compared to the Beta interferon and GA's. }\end{array}$ \\
\hline RESPOND ${ }^{34}$ & $\begin{array}{l}318(\text { received } \\
\geq 1 \text { dose of } \\
\text { DMF) }\end{array}$ & RRMS & $\begin{array}{l}\text { Observational } \\
\text { Study }\end{array}$ & 12 months & $\begin{array}{l}\text { SF-36 } \\
\text { MFIS-5 } \\
\text { TSQM-I4 } \\
\text { WPAI-MS } \\
\text { BDI-7 } \\
\text { PR-EDSS }\end{array}$ & $\begin{array}{l}\text { PR-EDSS and WPAI-MS scores remained stable and } \\
\text { others showed significant improvement compared to } \\
\text { the baseline }\end{array}$ \\
\hline $\begin{array}{l}\text { Interim Analysis } \\
\text { of ESTEEM } \\
45,46\end{array}$ & $\begin{array}{l}2025 \\
\text { (received } \geq 1 \\
\text { dose of DMF) }\end{array}$ & RRMS & $\begin{array}{l}\text { Observational } \\
\text { Study }\end{array}$ & 12 months & $\begin{array}{l}\text { MSIS-29 } \\
\text { MFIS-5 } \\
\text { EQ-5D-5L } \\
\text { VAS } \\
\text { WPAI-MS }\end{array}$ & $\begin{array}{l}\text { The scores from all measures } \\
\text { remained stable } \\
\text { compared to the baseline }\end{array}$ \\
\hline PROTEC ${ }^{47}$ & $\begin{array}{l}\text { II05 } \\
\text { (received } \geq 1 \\
\text { dose of DMF) }\end{array}$ & RRMS & $\begin{array}{l}\text { Observational } \\
\text { Study }\end{array}$ & 12 months & $\begin{array}{l}\text { MSIS-29 } \\
\text { MFIS-5 } \\
\text { TSQM-I4 } \\
\text { EQ-5D-5L } \\
\text { VAS } \\
\text { PRIMUS } \\
\text { WPAI-MS } \\
\text { BDI-7 }\end{array}$ & $\begin{array}{l}\text { The scores from all measures } \\
\text { showed significant improvement } \\
\text { except for PRIMUS which stayed stable } \\
\text { compared to the baseline }\end{array}$ \\
\hline
\end{tabular}

statistically significant improvement in the PCS scores compared to the placebo arm. EDSS scores at baseline were negatively correlated with PCS and MCS scores.
The investigators reported that among PwMS with EDSS scores $\geq 2.5$ at baseline, the percentage of patients who showed clinically meaningful ( $\Delta>5$ points) improvement 
in PCS and MCS scores favored the treatment arm as well, though this data was not explicitly provided in the paper. ${ }^{31}$

In addition, patients with disability progression scored significantly lower on the PCS and MCS compared to the group without disease progression at the end of two years. Thus, both the baseline EDSS scores and the change in the EDSS scores were associated with HRQoL in PwMS. Furthermore, the EQ-5D and GI-VAS also showed statistically significant improvement in both arms of the DMF group compared to the placebo arm at two years.

When compared to the GA treatment arm in the CONFIRM study, ${ }^{30}$ similar results were found for the DMF BID and TID treatment arms with respect to PROs. The participants treated with GA showed also significantly improved PRO scores compared to the placebo group. PRO benefits of the GA and DMF arms were broadly comparable but the study was not designed to prove the superiority of either treatment. ${ }^{30}$

\section{Respond}

The RESPOND (Effectiveness of DMF and its impact on PROs in suboptimal GA responders with RMS) study was a Phase 4, prospective, multicenter, open-label, single-arm, 12 -month observational trial. ${ }^{34}$ In this trial, the investigators assessed the effectiveness of DMF on PROs as secondary endpoints in patients with relapsing MS who switched to DMF due to suboptimal response to GA. The study utilized SF-36 as an HRQoL assessment tool as well as other PROs including: the Beck Depression Inventory fast screen (BDI-FS), ${ }^{35}$ the 5-item Modified Fatigue Impact Scale (MFIS-5), ${ }^{36}$ the 14-item Treatment Satisfaction Questionnaire for Medication (TSQM-14), ${ }^{37}$ the 8-item Moriski Medication Adherence Scale (MMAS-8) ${ }^{38}$ and the Patient Determined Disease Steps (PDDS). Baseline PRO scores were compared with scores twelve months later. $^{34}$

Investigators reported a statistically significant improvement compared to baseline in both the MCS component and the PCS component of the SF-36 (a mean change of $1.71[\mathrm{p}=0.0014]$ and $1.63[\mathrm{p}=0.02]$, respectively). It should be noted that this mean change, though statistically significant, does not reach the magnitude previously identified as a clinically important difference. ${ }^{39,40}$ The mean magnitude of change in SF36 components in the RESPOND study was less than that in DEFINE and CONFIRM. ${ }^{31}$ It is also important to note that change in SF-36 may have been lower among patients in the RESPOND study because they switched from an active comparator arm (GA), rather than comparison with placebo. It would have also been useful for authors in the RESPOND, DEFINE and CONFIRM studies to have provided data on the proportion of individuals who reached a clinically meaningful improvement in SF-36 upon treatment with DMF.

With respect to other PROs of interest, participants treated with DMF in RESPOND also demonstrated significant improvement in fatigue, as measured by the MFIS-5 (mean change $=-0.88[\mathrm{p}=0.0002)]$ ), and a statistically significant improvement in depressive symptoms as well (mean change in BDI-7 scores $=-0.54[p=0.0117]){ }^{34}$ In addition, PwMS taking DMF reported a statistically significant improvement in TSQM-14 scores overall, as well as in effectiveness, side effects and convenience subcomponents scores, over twelve months compared to baseline (p-value $<0.0001$ for all). ${ }^{34}$ Improvement in work productivity as measured via the Work Productivity and Activity Impairment-Multiple Sclerosis (WPAI-MS) scale $^{41}$ was also seen; PwMS on DMF had a significant mean change in WPAI-MS of $4.31[p=0.0201]){ }^{34}$

\section{Adelphi MS Disease Specific Program}

A cross-sectional study was performed which compared work productivity outcomes and HRQoL in PwMS who initiated on DMF with those taking other DMTs; specifically, interferon beta $1 \mathrm{a}, 1 \mathrm{~b}$ or $\mathrm{GA}^{4}{ }^{42}$ The data was pulled from Adelphi MS Disease Specific Programme, a multinational cross-sectional study with 2965 RRMS and 494 SPMS patients. ${ }^{42}$ Thirty-one patients from the DMF treatment group and 229 patients from the other therapies group who completed at least one WPAI-MS assessment or an HRQoL measurement were included in this study. Investigators found that patients treated with DMF were more likely to be employed full-time and were less likely to have retired due to MS. The WPAI score was also higher in the DMF group, indicating that the PwMS treated with DMF had better overall work impairment, absenteeism and presenteeism scores and less work and activity impairment compared to those being treated with other DMTs (estimated average treatment effects [ATE] on subscales of WPAI for work impairment $=-13.92$, $\mathrm{p}$-value $\leq 0.001$, absenteeism $=-2.06, \mathrm{p}$-value $=0.012$, and presenteeism $=-12.97$, p-value $<0.001$ ).

Patients treated with DMF also demonstrated better HRQoL assessment based upon reported improvement in The Hamburg Quality of Life Questionnaire for Multiple Sclerosis (HAQUAMS) ${ }^{43}$ and EQ-5D. Regression analysis 
between HRQoL and WPAI-MS results further indicated that better quality of life was associated with improvement in work productivity. ${ }^{42}$ It is important to note that there were only thirty-one DMF patients in the Adelphi database, which significantly limits the conclusions that can be drawn from this analysis. Furthermore, these results were not interpreted within the context of clinically meaningful change on any of these PRO scales. In particular, difference in the HAQUAMS between PwMS treated with DMF and PwMS treated with other DMTs was relatively small in magnitude, though statistically significant for better outcomes.

\section{Esteem}

ESTEEM ("A multicenter, global, observational study to collect information on safety and to document the drug utilization of Tecfidera [dimethyl fumarate] when used in routine medical practice in the treatment of multiple sclerosis") is a 5-year prospective, non-interventional study that is ongoing. ${ }^{44}$ In this study, 2025 patients who had received at least one dose of DMF were followed and PRO measures were reported as secondary endpoints assessed at baseline, twelve and twentyfour months. The Multiple Sclerosis Impact Scale (MSIS-29), EQ-5D-5L and EQ-VAS were utilized as HRQoL assessments. Other PRO measures reported in this study include the MFIS-5 and WPAI-MS. At both follow-up timepoints, PRO scores remained stable or improved compared to baseline; in particular, participants reported improvement in the psychological component of the MSIS-29, the MFIS-5 and all subscales of the WPAI-MS. ${ }^{45}$ Scores on the physical impact component of the MSIS-29, on the EQ-5D-5L and on the EQVAS remained stable. ${ }^{45}$ However, the investigators cautioned that they were unable to determine a clinically meaningful change for this measure, which is a problem for many PROs utilized for PwMS. ${ }^{45,46}$

Subgroup analyses were also performed after twenty-four months of follow up and the participants were grouped into three categories: newly diagnosed, early MS patients, and those switching from interferons or glatiramer acetate to DMF. $^{45}$ While all subgroups showed a similar trend to the total study population, there was no comparison made directly between groups. This was true for PROs as well as annualized relapse rate (ARR) which was a primary endpoint of this study.

\section{Protec}

PROTEC ("A multicenter, open-label study evaluating the effectiveness of oral tecfidera [dimethyl fumarate] on MS disease activity and patient-reported outcomes in subjects with relapsing-remitting multiple sclerosis in the real-world setting") is a phase IV, open-label, single-arm study conducted in Canada and Europe. In this study, 1105 patients received at least one dose of DMF and PRO measures were reported as secondary end-points and assessed at baseline and twelve months. ${ }^{47}$ The MSIS-29 and EQ-5D-5L VAS were utilized as HRQoL assessments. Other PRO measures reported in the study were: MFIS-5, TSQM-14, WPAI-MS, BDI-Fast Screen and the activity scale portion of PRIMUS. A statistically significant improvement in HRQoL outcomes, including physical $(n=868)$ and psychological $(n=869)$ components of MSIS-29 and EQ-5D-5L ( $\mathrm{n}=803)$ was reported. Patients taking DMF also reported statistically significant improvements in fatigue (MFIS-5), depression (utilizing the BDI-fast screen), treatment satisfaction (as measured via the TSQM-14), and work productivity outcomes (WPAI-MS). There were no statistically significant changes in the activity scale of the PRIMUS during this study. ${ }^{47}$

Subgroup analyses were performed in PROTEC as well. Participants were grouped into four categories: newly diagnosed patients (classified as patients diagnosed within the prior 1 year and who were naïve to MS-approved DMTs), patients with an EDSS $\leq 3.5$, patients with $\leq 1$ relapse in the prior year, and patients who had both a baseline EDSS $\leq 3.5$ and $\leq 1$ relapse in the prior year. ${ }^{47}$ All subgroups demonstrated a statistically significant improvement in the MSIS29, MFIS-5 and EQ-5D-5L VAS from baseline to 12 months.

\section{Perspectives}

Though studies are limited, evaluation of DMF via PROs are generally favorable. DMF was associated with improved quality of life outcomes both physically and psychologically in most of the six available studies, both with generic and MS-specific HRQoL assessment tools. PROs have also been reported as secondary or tertiary outcomes for other DMTs in phase 3 clinical trials with active comparators. The SF-36 and MS functional composite score (MSFC) have been utilized as PRO measures for ocrelizumab in OPERA I and II studies ${ }^{48}$ and analyses of several PROs have also been reported for alemtuzumab in CARE-MS I and II phase 3 clinical trials. ${ }^{49,50}$

It is important to acknowledge that there are several limitations with respect to the study of PROs in PwMS. Many PRO measures used in PwMS have not been validated in MS-specific populations. Clinical trials and other studies typically utilize PROs as secondary or tertiary endpoints; therefore, these studies are not powered for PROs and PROs are often part of post hoc analyses. 
Further studies to develop and validate PROs in MSspecific populations are needed. This review was limited to the scope of PROs used in studies of DMF and excluded other MS medications due to publication size constraints.

As demonstrated through this review of studies on PROs in PwMS treated with DMF, PROs are increasingly recognized as important as not only an approach for rigorous clinical evaluation of a drug, but also as real-world measures that are meaningful to the patient on a personal level. Since the tolerability of a medication affects treatment adherence and thus efficacy, the importance of acquiring this information cannot be overstated for a better patient-centered approach to medical care. In the US, the Center for Device and Radiological Health at the FDA was an early adopter of the use of PROs for device approvals and is continuing to expand the inclusion of PROs in regulatory decisions. PRO measures are a qualifying clinical outcome assessment for drug development at the Center for Drug Evaluation and Research at the FDA. Federally-funded studies now encourage the inclusion of PROs. The Patient-Centered Outcomes Research Institute (PCORI) was established by Congress in 2010 through the Patient Protection and Affordable Care Act, and funds studies with an emphasis on research guided by patients and caregivers. Inclusion of PROs is likely to become more important in determining quality of care in the Merit-based Incentive Payment System as well.

The goal of PRO use is to be able to increase patient engagement in disease management by gaining insight into disease perception of the patient for a more "patientcentered" approach. Many MS patients have difficulty interpreting clinical trial data when choosing an MS medication. ${ }^{51}$ In fact, patients often turn to social media and online support groups for guidance from other MS patients on DMT selection. As demonstrated in this review, a recent study indicated that PROs may predict disability worsening among PwMS and can be used in conjunction with objective clinical findings and imaging to guide DMT management. ${ }^{10}$ With appropriate validation in relevant populations, PROs could be useful in the clinical setting, as they can provide a scientific outcome measure of patient perspectives and personal experience with DMTs, in addition to the traditionally used clinical outcome measures. As PROs are increasingly utilized in the context of clinical trial design and post-marketing measures of efficacy, current barriers including lack of expertise, lack of regulatory predictability and impact of PROs should be surmounted.

\section{Disclosure}

CV reports grants from Biogen, during the conduct of the study; personal fees from Merck/EMD Serono, outside the submitted work. BWG has received personal compensation (grants and/or personal fees) from Biogen Idec, Teva Neuroscience, EMD Serono, Novartis, Genzyme, Sanofi, Celgene and Genentech for speaking and consultant fees, and personal fees from Abbvie, outside the submitted work; they also participated in advisory boards for and have received research support from Biogen Idec, EMD Serono, Novartis, Genentech, Mallinckrodt Pharmaceuticals and Celgene. The authors report no other conflicts of interest in this work.

\section{References}

1. Gold R, Kappos L, Arnold DL, et al. Placebo-controlled phase 3 study of oral BG-12 for relapsing multiple sclerosis. $N$ Engl J Med. 2012;367(12):1098-1107. doi:10.1056/NEJMoa1114287

2. Fox RJ, Miller DH, Phillips JT, et al. Placebo-controlled phase 3 study of oral BG-12 or glatiramer in multiple sclerosis. $N$ Engl $J$ Med. 2012;367(12):1087-1097. doi:10.1056/NEJMoa1206328

3. Bomprezzi R. Dimethyl fumarate in the treatment of relapsing-remitting multiple sclerosis: an overview. Ther $A d v$ Neurol Disord. 2015;8(1):20-30. doi:10.1177/1756285614564152

4. Nowinski CJ, Miller DM, Cella D. Evolution of patient-reported outcomes and their role in multiple sclerosis clinical trials. Neurotherapeutics. 2017;14(4):934-944. doi:10.1007/s13311-017-0571-6

5. Rothwell PM, McDowell Z, Wong CK, Dorman PJ. Doctors and patients don't agree: cross sectional study of patients' and doctors' perceptions and assessments of disability in multiple sclerosis. BMJ (Clin Res Ed). 1997;314(7094):1580-1583. doi:10.1136/bmj.314.7094.1580

6. Janse AJ, Gemke RJ, Uiterwaal CS, van der Tweel I, Kimpen JL, Sinnema G. Quality of life: patients and doctors don't always agree: a meta-analysis. J Clin Epidemiol. 2004;57(7):653-661. doi:10.1016/ j.jclinepi.2003.11.013

7. United States Food and Drug Adminstration. Guidance for Industry. Patient-reported outcome measures: use in medical product development to support laveling claims. 2009; Available from: https://www. fda.gov/regulatory-information/search-fda-guidance-documents /patient-reported-outcome-mreasures-use-medical-productdevelopment-support-labeling-claims. Accessed June 6, 2019.

8. Kremenchutzky M, Walt L. Perceptions of health status in multiple sclerosis patients and their doctors. Can J Neurol Sci. 2013;40 (2):210-218. doi:10.1017/S0317167100013755

9. Ysrraelit MC, Fiol MP, Gaitan MI, Correale J. Quality of life assessment in multiple sclerosis: different perception between patients and neurologists. Front Neurol. 2017;8:729. doi:10.3389/fneur.2017.00729

10. Vaughn CB, Kavak KS, Dwyer MG, et al. Fatigue at enrollment predicts EDSS worsening in the New York state multiple sclerosis consortium. Mult Scler. 2018;1352458518816619.

11. Gnanasakthy A, Lewis S, Clark M, Mordin M, DeMuro C. Potential of patient-reported outcomes as nonprimary endpoints in clinical trials. Health Qual Life Outcomes. 2013;11:83. doi:10.1186/1477-7525-11-83

12. Khurana V, Sharma H, Afroz N, Callan A, Medin J. Patient-reported outcomes in multiple sclerosis: a systematic comparison of available measures. Eur J Neurol. 2017;24(9):1099-1107. doi:10.1111/ene.2017.24.issue-9

13. Cella D, Riley W, Stone A, et al. The Patient-Reported Outcomes Measurement Information System (PROMIS) developed and tested its first wave of adult self-reported health outcome item banks: 2005-2008. J Clin Epidemiol. 2010;63(11):1179-1194. doi:10.1016/ j.jclinepi.2010.04.011 
14. National Institute on Aging. Patient-Reported Outcomes Measurement Information System (PROMIS). Available from: https://www.nia.nih.gov/research/resource/patient-reported-outcomes -measurement-information-system-promis. Accessed June 1, 2019.

15. Lavallee D, Chenok K, Love R, et al. Incorporating patient-reported outcomes into health care to engage patients and enhance care. Health Aff. 2016;35(4):575-582. doi:10.1377/hlthaff.2015.1362

16. D'Amico E, Haase R, Review: ZT. Patient-reported outcomes in multiple sclerosis care. Mult Scler Relat Disord. 2019;33:61-66. doi:10.1016/j.msard.2019.05.019

17. Kornberg MD, Bhargava P, Kim PM, et al. Dimethyl fumarate targets GAPDH and aerobic glycolysis to modulate immunity. Science (New York, NY). 2018;360(6387):449-453. doi:10.1126/science.aan4665

18. da Fonseca RR, Johnson WE, O'Brien SJ, Vasconcelos V, Antunes A. Molecular evolution and the role of oxidative stress in the expansion and functional diversification of cytosolic glutathione transferases. BMC Evol Biol. 2010;10:281. doi:10.1186/1471-2148-10-281

19. Ma Q. Role of nrf2 in oxidative stress and toxicity. Аnпи Rev Pharmacol Toxicol. 2013;53:401-426. doi:10.1146/annurev-pharmtox-011112-140320

20. Ryter SW, Alam J, Choi AM. Heme oxygenase-1/carbon monoxide: from basic science to therapeutic applications. Physiol Rev. 2006;86 (2):583-650. doi:10.1152/physrev.00011.2005

21. Siegel D, Gustafson DL, Dehn DL, et al. oxidoreductase 1: role as a superoxide scavenger. Mol Pharmacol. 2004;65(5):1238-1247. doi:10.1124/mol.65.5.1238

22. Longbrake EE, Ramsbottom MJ, Cantoni C, Ghezzi L, Cross AH, Piccio L. Dimethyl fumarate selectively reduces memory T cells in multiple sclerosis patients. Mult Scler. 2016;22(8):1061-1070. doi:10.1177/ 1352458515608961

23. Spencer CM, Crabtree-Hartman EC, Lehmann-Horn K, Cree BA, Zamvil SS. Reduction of CD8(+) T lymphocytes in multiple sclerosis patients treated with dimethyl fumarate. Neurol Neuroimmunol Neuroinflamm. 2015;2(3):e76. doi:10.1212/NXI.0000000000000076

24. Mathias A, Perriot S, Canales M, et al. Impaired T-cell migration to the CNS under fingolimod and dimethyl fumarate. Neurol Neuroimmunol Neuroinflamm. 2017;4(6):e401. doi:10.1212/NXI.0000000000000401

25. Kihara Y, Groves A, Rivera RR, Chun J. Dimethyl fumarate inhibits integrin alpha4 expression in multiple sclerosis models. Ann Clin Transl Neurol. 2015;2(10):978-983. doi:10.1002/acn3.251

26. Peng H, Li H, Sheehy A, Cullen P, Allaire N, Scannevin RH. Dimethyl fumarate alters microglia phenotype and protects neurons against proinflammatory toxic microenvironments. J Neuroimmunol. 2016;299:35-44. doi:10.1016/j.jneuroim.2016.08.006

27. Munoz MA, Kulick CG, Kortepeter CM, Levin RL, Avigan MI. Liver injury associated with dimethyl fumarate in multiple sclerosis patients. Mult Scler. 2017;23(14):1947-1949. doi:10.1177/1352458516688351

28. Briner M, Bagnoud M, Miclea A, et al. Time course of lymphocyte repopulation after dimethyl fumarate-induced grade 3 lymphopenia: contribution of patient age. Ther Adv Neurol Disord. 2019;12:1756286 419843450. doi:10.1177/1756286419843450

29. Kappos L, Gold R, Arnold DL, et al. Quality of life outcomes with BG-12 (dimethyl fumarate) in patients with relapsing-remitting multiple sclerosis: the DEFINE study. Mult Scler. 2014;20(2):243-252. doi: $10.1177 / 1352458513507817$

30. Kita M, Fox RJ, Phillips JT, et al. Effects of BG-12 (dimethyl fumarate) on health-related quality of life in patients with relapsing-remitting multiple sclerosis: findings from the CONFIRM study. Mult Scler. 2014;20(2):253-257. doi:10.1177/1352458513507818

31. Kita M, Fox RJ, Gold R, et al. Effects of delayed-release dimethyl fumarate (DMF) on health-related quality of life in patients with relapsing-remitting multiple sclerosis: an integrated analysis of the phase 3 DEFINE and CONFIRM studies. Clin Ther. 2014;36 (12):1958-1971. doi:10.1016/j.clinthera.2014.08.013
32. McHorney C, Raczek JA. The MOS 36-item short-form health survey (SF-36): II. Psychometric and clinical tests of validity in measuring physical and mental health constructs. Medicare Care. 1993;31 (3):247-263. doi:10.1097/00005650-199303000-00006

33. EuroQol Group..EuroQol-a new facility for the measurement of health-related quality of life. Health Policy. 1990;16(3):199-208. doi:10.1016/0168-8510(90)90421-9

34. Kresa-Reahl K, Repovic P, Robertson D, Okwuokenye M, Meltzer L, Mendoza JP. Effectiveness of delayed-release dimethyl fumarate on clinical and patient-reported outcomes in patients with relapsing multiple sclerosis switching from glatiramer acetate: RESPOND, a prospective observational study. Clin Ther. 2018;40(12):2077-2087. doi:10.1016/j. clinthera.2018.10.011

35. Benedict RH, Fishman I, McClellan MM, Bakshi R, WeinstockGuttman B. Validity of the beck depression inventory-fast screen in multiple sclerosis. Mult Scler. 2003;9(4):393-396. doi:10.1191/ $1352458503 \mathrm{~ms} 902 \mathrm{oa}$

36. Mills RJ, Young CA, Pallant JF, Tennant A. Rasch analysis of the Modified Fatigue Impact Scale (MFIS) in multiple sclerosis. J Neurol Neurosurg Psychiatry. 2010;81(9):1049-1051. doi:10.1136/jnnp.2008.151340

37. Atkinson MJ, Sinha A, Hass SL, et al. Validation of a general measure of treatment satisfaction, the Treatment Satisfaction Questionnaire for Medication (TSQM), using a national panel study of chronic disease. Health Qual Life Outcomes. 2004;2:12. doi:10.1186/1477-7525-2-12

38. Krousel-Wood M, Islam T, Webber LS, Re RN, Morisky DE, Muntner P. New medication adherence scale versus pharmacy fill rates in seniors with hypertension. Am J Manag Care. 2009;15(1):59-66.

39. Wyrwich K, Tierney W, Babu A, Kroenke K, Wolinsky F. A comparison of clinically important differences in health-related quality of life for patients with chronic lung disease, asthma, or heart disease. Health Serv Res. 2005;40(2):577-592. doi:10.1111/ hesr.2005.40.issue-2

40. Ward M, Guthrie L, Alba M. Clinically important changes in short-form-36 scales for use in rheumatoid arthritis clinical trials: the impact of low responsiveness. Arthritis Care Res (Hoboken). 2014;66(12):1783-1789. doi:10.1002/acr.22392

41. Glanz BI, Degano IR, Rintell DJ, Chitnis T, Weiner HL, Healy BC. Work productivity in relapsing multiple sclerosis: associations with disability, depression, fatigue, anxiety, cognition, and health-related quality of life. Value Health. 2012;15(8):1029-1035. doi:10.1016/j.jval.2012.07.010

42. Lee A, Pike J, Edwards MR, Petrillo J, Waller J, Jones E. Quantifying the benefits of dimethyl fumarate over beta interferon and Glatiramer acetate therapies on work productivity outcomes in MS Patients. Neurol Ther. 2017;6(1):79-90. doi:10.1007/s40120-016-0061-5

43. Gold SM, Heesen C, Schulz H, et al. Disease specific quality of life instruments in multiple sclerosis: validation of the Hamburg Quality of Life Questionnaire in Multiple Sclerosis (HAQUAMS). Mult Scler. 2001;7(2):119-130. doi:10.1177/135245850100700208

44. Dimethyl fumarate (DMF) observational study (ESTEEM). 2019; Available from: https://clinicaltrials.gov/ct2/show/NCT02047097.

45. Giles K, Balashov K, Jones C, et al. Real-World Efficacy of DelayedRelease Dimethyl Fumarate in Early Multiple Sclerosis: Interim Results from ESTEEM. Philadelphia, PA, USA: American Academy of Neurology Annual Meeting; 2019.

46. Everage N, Prada C, Liu S, et al. Safety and efficacy of delayed-release dimethyl fumarate in multiple sclerosis patients treated in routine medical practice: interim analysis of ESTEEM (P6.333). American Academy of Neurology Annual Meeting; 2017; Boston, MA, USA.

47. Berger T, Brochet B, Confalonieri $\mathrm{P}$, et al. Effectiveness of delayed-release dimethyl fumarate on clinical measures and patient-reported outcomes in newly diagnosed and other early relapsing-remitting multiple sclerosis patients: subgroup analysis of PROTEC. American Academy of Neurology Annual Meeting; 2017; Boston, MA, USA. 
48. Hauser SL, Bar-Or A, Comi G, et al. Ocrelizumab versus interferon beta-1a in relapsing multiple sclerosis. $N$ Engl $J$ Med. 2017;376 (3):221-234. doi:10.1056/NEJMoa1601277

49. Cohen JA, Coles AJ, Arnold DL, et al. Alemtuzumab versus interferon beta 1a as first-line treatment for patients with relapsing-remitting multiple sclerosis: a randomised controlled phase 3 trial. Lancet (London, England). 2012;380(9856):1819-1828. doi:10.1016/S0140-6736(12)61769-3

50. Coles AJ, Twyman CL, Arnold DL, et al. Alemtuzumab for patients with relapsing multiple sclerosis after disease-modifying therapy: a randomised controlled phase 3 trial. Lancet (London, England). 2012;380(9856):1829-1839. doi:10.1016/S0140-6736(12)61768-1

51. Fischer JS, LaRocca NG, Miller DM, Ritvo PG, Andrews H, Paty D. Recent developments in the assessment of quality of life in multiple sclerosis (MS). Mult Scler. 1999;5(4):251-259. doi:10.1177/ 135245859900500410

52. Cella DF, Dineen K, Arnason B, et al. Validation of the functional assessment of multiple sclerosis quality of life instrument. Neurology. 1996;47(1):129-139. doi:10.1212/WNL.47.1.129

53. Vickrey BG, Hays RD, Harooni R, Myers LW, Ellison GW. A health-related quality of life measure for multiple sclerosis. Qual Life Res. 1995;4(3):187-206. doi:10.1007/BF02260859

54. Krupp LB, LaRocca NG, Muir-Nash J, Steinberg AD. The fatigue severity scale. Application to patients with multiple sclerosis and systemic lupus erythematosus. Arch Neurol. 1989;46(10):1121-1123. doi:10.1001/archneur.1989.00520460115022

55. Meads DM, Doward LC, McKenna SP, Fisk J, Twiss J, Eckert B. The development and validation of the Unidimensional Fatigue Impact Scale (U-FIS). Mult Scler. 2009;15(10):1228-1238. doi:10.1177/ 1352458509106714

56. Penner IK, Raselli C, Stocklin M, Opwis K, Kappos L, Calabrese P. The Fatigue Scale for Motor and Cognitive Functions (FSMC): validation of a new instrument to assess multiple sclerosis-related fatigue. Mult Scler. 2009;15(12):1509-1517. doi:10.1177/1352458509348519

57. Mills RJ, Young CA, Pallant JF, Tennant A. Development of a patient reported outcome scale for fatigue in multiple sclerosis: the Neurological Fatigue Index (NFI-MS). Health Qual Life Outcomes. 2010;8:22.

58. Schwartz CE, Vollmer T, Lee H. Reliability and validity of two self-report measures of impairment and disability for MS. North American Research Consortium on Multiple Sclerosis Outcomes Study Group. Neurology. 1999;52(1):63-70. doi:10.1212/WNL.52.1.63

59. Gulick EE. Model confirmation of the MS-related symptom checklist. Nurs Res. 1989;38(3):147-153. doi:10.1097/00006199-19890500000012

60. Noordhoff TC, Scheepe JR, t Hoen LA, Sluis TAR, Blok BFM. The Multiple Sclerosis Intimacy and Sexuality Questionnaire (MSISQ-15): validation of the Dutch version in patients with multiple sclerosis and spinal cord injury. Neurourol Urodyn. 2018;37 (8):2867-2874. doi:10.1002/nau.23804

61. Burks J, Chancellor M, Bates D, et al. Development and validation of the actionable bladder symptom screening tool for multiple sclerosis patients. Int J MS Care. 2013;15(4):182-192. doi:10.7224/15372073.2012-049

62. Learmonth YC, Motl RW, Sandroff BM, Pula JH, Cadavid D. Validation of patient determined disease steps (PDDS) scale scores in persons with multiple sclerosis. BMC Neurol. 2013;13:37. doi:10.1186/1471-2377-13-37
63. Wicks P, Vaughan TE, Massagli MP. The multiple sclerosis rating scale, revised (MSRS-R): development, refinement, and psychometric validation using an online community. Health Qual Life Outcomes. 2012;10:70. doi:10.1186/1477-7525-10-70

64. Hobart J, Lamping D, Fitzpatrick R, Riazi A, Thompson A. The Multiple Sclerosis Impact Scale (MSIS-29): a new patient-based outcome measure. Brain. 2001;124(Pt 5):962-973. doi:10.1093/brain/124.5.962

65. Hobart JC, Riazi A, Lamping DL, Fitzpatrick R, Thompson AJ. Measuring the impact of MS on walking ability: the 12-Item MS Walking Scale (MSWS-12). Neurology. 2003;60(1):31-36. doi:10. 1212/WNL.60.1.31

66. Granger C. The LIFEware system. J Rehabil Outcomes Meas. 1999;3:63-69.

67. Finlayson ML, Peterson EW, Fujimoto KA, Plow MA. Rasch validation of the falls prevention strategies survey. Arch Phys Med Rehabil. 2009;90(12):2039-2046. doi:10.1016/j.apmr.2009.07.013

68. Rigby SA, Domenech C, Thornton EW, Tedman S, Young CA. Development and validation of a self-efficacy measure for people with multiple sclerosis: the multiple sclerosis self-efficacy scale. Mult Scler. 2003;9(1):73-81. doi:10.1191/1352458503ms870oa

69. Schwartz CE, Coulthard-Morris L, Zeng Q, Retzlaff P. Measuring self-efficacy in people with multiple sclerosis: a validation study. Arch Phys Med Rehabil. 1996;77(4):394-398. doi:10.1016/S00039993(96)90091-X

70. Airlie J, Baker GA, Smith SJ, Young CA. Measuring the impact of multiple sclerosis on psychosocial functioning: the development of a new self-efficacy scale. Clin Rehabil. 2001;15(3):259-265. doi:10.1191/026921501668362643

71. Young CA, Mills RJ, Woolmore J, Hawkins CP, Tennant A. The unidimensional self-efficacy scale for MS (USE-MS): developing a patient based and patient reported outcome. Mult Scler. 2012;18 (9):1326-1333. doi:10.1177/1352458512436592

72. Giordano A, Uccelli MM, Pucci E, et al. The multiple sclerosis knowledge questionnaire: a self-administered instrument for recently diagnosed patients. Mult Scler. 2010;16(1):100-111. doi:10.1177/ 1352458509352865

73. Benedict RH, Munschauer F, Linn R, et al. Screening for multiple sclerosis cognitive impairment using a self-administered 15-item questionnaire. Mult Scler. 2003;9(1):95-101. doi:10.1191/135245 $8503 \mathrm{~ms} 861$ oa

74. Lovera J, Bagert B, Smoot $\mathrm{KH}$, et al. Correlations of perceived deficits questionnaire of multiple sclerosis quality of life inventory with beck depression inventory and neuropsychological tests. $J$ Rehabil Res Dev. 2006;43(1):73-82. doi:10.1682/JRRD.2004. 09.0118

75. Pakenham KI. The nature of caregiving in multiple sclerosis: development of the caregiving tasks in multiple sclerosis scale. Mult Scler. 2007;13(7):929-938. doi:10.1177/1352458507076973

76. Pakenham KI. Making sense of caregiving for persons with multiple sclerosis (MS): the dimensional structure of sense making and relations with positive and negative adjustment. Int J Behav Med. 2008;15(3):241-252. doi:10.1080/10705500802222345

77. Pakenham KI, Cox S. Development of the benefit finding in multiple sclerosis (MS) caregiving scale: a longitudinal study of relations between benefit finding and adjustment. $\mathrm{Br} \mathrm{J}$ Health Psychol. 2008;13(Pt 4):583-602. doi:10.1348/135910707X250 848 


\section{Publish your work in this journal}

Patient Related Outcome Measures is an international, peer-reviewed, open access journal focusing on treatment outcomes specifically relevant to patients. All aspects of patient care are addressed within the journal and practitioners from all disciplines are invited to submit their work as well as healthcare researchers and patient support groups.
The manuscript management system is completely online and includes a very quick and fair peer-review system. Visit http://www. dovepress.com/testimonials.php to read real quotes from published authors.

Submit your manuscript here: http://www.dovepress.com/patient-related-outcome-measures-journal 